\title{
THE LIVED EXPERIENCE OF BEING A SPEECH-LANGUAGE THERAPIST IN THE WESTERN CAPE PUBLIC HEALTH SERVICE
}

Jocelyn A. Warden, Patricia Mayers and Harsha Kathard Division of Communication Sciences and Disorders, University of Cape Town, South Africa

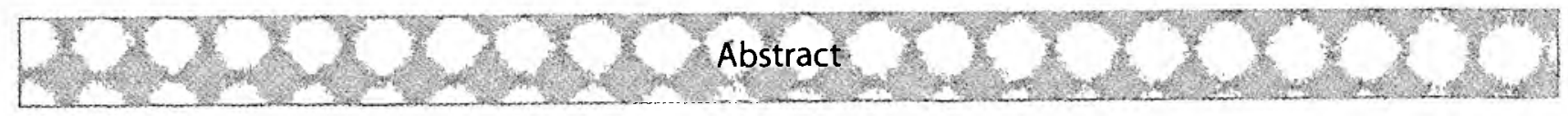

This study explores the lived experience of being a Speech-Language Therapist ( $S$ - $L$ Therapist) in the South African Western Cape public health service. The lived experience of seven S-LTherapists with varied clinical experience was illuminated using a qualitative phenomenological research design. S-LTherapists, working in the threeWestern Cape tertiary hospitals, provided an in-depth account of their experiences as S-LTherapists.Theaudiorecordedinterviewswere transcribedverbatimandanalysedusinganadaptation ofColaizzi's (1978) method of analysis. The rigour and trustworthiness of the research process was informed by consideration of issues of credibility, applicability, confirmability and dependability as they relate to phenomenological design. Five main themes emerged from data analysis: expectations of practice and practice realities; being part of the"underdog"profession:role definitionandstatus; being connected; theholisticnature of the S-LTherapist's practice; and erosion or promotion. The implicationsfor training and support of S-L therapists by managers and policymakers and peers are highlighted.

Keywords: phenomenology, lived experience, Western Cape public health service, Speech-Language Therapist.

$\mathrm{T}$ This study responds to the question: What is the essence of the lived experience of S-

$L$ Therapists in a rapidly changing public health system in the Western Cape? 'Lived experience' studies (phenomenology) examine human experience through descriptions provided by the people who have the experience of the phenomenon under investigation. Phenomenology aims to describe how people experience a specific phenomenon, how they interpret those experiences and what meaning the experiences hold for them. Research of this nature uses the person's description of their experience to "transform lived experience into a textual expression of its essence" (Van Manen, 1990, p. 36). While phenomenological research in the field of S-L Therapy has focused primarily on people living with certain communication disorders such as aphasia and dysfluency, this study focuses on professional issues by $\mathrm{ex}^{-}$ ploring the lived experience of S-L Therapists themselves.

Research in South Africa has focussed on burnout amongst S-L Therapists (Swidler \& Ross, 1993), threats to the profession within the South African context (Tuomi, 1994), quality assurance in SpeechLanguage Pathology and Audiology within the South African context (Tuomi, 1994), and training needs to meet the needs of communicatively impaired South Africans (Bortz, Jardine, \& Tshule, 1996). International studies have researched issues such as the effect of extrinsic and intrinsic job satisfaction factors on retention of S-L Therapists (Randolph, 2005), issues of gender imbalance in the profession (Boyd \& Hewlett, 2001; Sheridan, 1999), the patient-professional relationship (Stone, 1992), the effect of personal and professional value imbalance on dissatisfaction (Byng, Cairns, \& Duchan, 2002) .

Speech-Language Therapy (S-L Therapy) services in the Western Cape are managed primarily by the Department of Health. The post-apartheid service provision for health care in general is underpinned by principles of Primary Health Care (van Rensburg, 2004) and implemented through the District Health System. Since 1994, health service delivery in the Western Cape has undergone rapid change as accessibility of services to indigent communities has been extended. Major reorientation of services has occurred at primary, secondary and tertiary levels of care across the health sector. Despite this reorientation, S-L Therapists have remained primarily in the three tertiary hospitals, namely Red Cross Children's War Memorial Hospital (RXH), Groote Schuur Hospital (GSH) and Tygerberg Hospital (TBH) 
limiting service delivery at primary or secondary levels.

As a consequence of the imperatives for transformation of service delivery in South Africa, the demography of the client population and variety of settings in which South African S-L Therapists provide services has changed and expanded. Significant theoretical, clinical and technological advances in the field of S-L Therapy (Aron, 1991) together with the social and political changes since 1994 have significant implications for the training of S-L Therapists. In the current context, S-L Therapists are challenged to meet new service delivery imperatives and, in this rapidly changing context, it is vital to understand their lived experience.

Tuomi reported that the profession and professionals were considered to be showing "signs of strain" $(1994$, p. 6). Challenges facing the profession were projected to be the management of the diversity of people, cultures and language groups, a phenomenon also described by Henri and Hallowell (2001) in respect of the international context. Even though historically S-L Therapists have had "little experience and often little inclination to participate in the arena of political advocacy and lobbying" (Lubinski \& Frattali, 2001, p. 344), there has been a significant increase in the need for advocacy worldwide (Lubinski \& Frattali, 2001). The predicted changes that Aron and Tuomi described are unravelling in the current context, providing impetus for this study.

While contextual influences present a challenge, the nature of the work of S-L Therapists influences their reality. As part of a helping profession S-L Therapists are "first and foremost helpers" (Purtilo, 1990, p. 18) as they benefit the individual in society, and patients' lives are directly or indirectly affected by their activities.

Another dimension of S-L Therapy practice is one of forging identity. "Throughout history, the discipline of human communication sciences and disorders as well as Speech-Language Pathologists have worked aggressively to form an identity that is unique from other disciplines, and have earned a reputation of being specialists in the field of communication and related disorders" (Frattali, 2001, p. 173). This, however, can lead to a professional identity so separate from other professions that it becomes a professional liability "if pursued as propriety and at the exclusion of other professionals" (p. 173). S-L Therapists are encouraged to adopt interdisciplinary or multidisciplinary approaches to treatment (Frattali, 2001). The focus on co-ordination and communication between members brings together diverse skills for the achievement of goals.

The centrality as well as the changing nature of the clinical relationship is a key element in effective service delivery in communication disorders and other helping professions (Stone, 1992). S-L Therapy intervention as well as other healthcare interventions take place in a context of an - interaction between the patient and professional - a relationship documented as early as 1937 (Bloom \& Summey, 1978). Models of the professional-patient relationship have changed significantly from distinctly asymmetrical models (Parsons, as cited in Bloom \& Summey, 1978) where the professional was assigned specific privileges such as professional self-regulation, access to physical and personal intimacy with the patient, autonomy and professional dominance.
Recent models describe a mutual participation (Fadlon \& Werner, 1999) and an encounter of cultures, background, families and aspirations. As the S-L Therapist-patient relationship develops, it creates its own "dynamic quality that is affected by what the S-L Therapist and client bring to it" (Flasher \& Fogle, 2004, p. 87). The trust which develops between the S-L Therapists and their patients has been referred to as "professional closeness" (Purtilo, 1990, p. 22) and the manner in which the client behaves toward the $\mathrm{S}$ L Therapist is suggested to be directly linked to how the S-L Therapist thinks, feels and behaves towards the client (Flasher \& Fogle, 2004, p. 88).

The approach of the medical profession to the management of illness, disease and disability has changed significantly over the last few decades (Sahler, 2002). As more medical professionals have begun to appreciate the patient's right and desire to participate in the management of his or her illness, the patient is no longer seen as a passive recipient of medical science and treatment. This has led to health professionals taking a more holistic approach described by Engel (1977) as the biopsychosocial model of healthcare. This model recognizes other aspects of the person as possible contributing factors to the presenting problem. The shift in the management of patients, illness and disease has impacted significantly on the S-L Therapy practice, particularly at a relational level.

The hybrid nature of the S-L Therapy profession, which draws on fields such as neurology, psychology, anatomy, physiology, physics, education and computer science makes it a highly integrated profession that is not limited to one approach to the treatment of patients and their disorders. This makes the profession consistent with the principles that guide the biopsychosocial model of healthcare.

As a consequence of the complex range of issues shaping the work of S-L Therapists, and those involved in "people work" (Farmer, Monahan, \& Hekeler, 1984, p. 43), many stress-related factors have been described. Factors which are inherently stressful within human service professions include the complexity of clients and their needs, the difficulty in evaluating success, the poor perceptions of the helping relationship by others, lack of support from the organization, ambiguous decision-making processes, and tension of client needs and organization demands (Farmer et al., 1984, p. 45). Maslach (1982) stated of health professions that "because by definition the recipients of most helping relationships are people with problems, the health professional inevitably sees the part of her patient that is negative or needing intervention" (p. 18).

A major source of stress for S-L Therapy professionals is that of conflicting priorities in settings where S-L Therapy intervention is regarded as merely a supportive function within the hospital team (Byng et al., 2002). The only published South African study on burnout among S-L Therapists reported that, at the time of this study, S-L Therapists and Audiologists were experiencing moderate levels of emotional exhaustion, low levels of depersonalization, and high levels of personal accomplishment. Hospital therapists in particular perceived themselves as being under large amounts of pressure and susceptible to burnout (Swidler \& Ross, 1993). 
Organizations in which people work, create motivation through factors that are either intrinsic or extrinsic to the work itself (Bratten, Callinan, Forshaw, \& Sawchuk, 2007). Reporting on extrinsic and intrinsic factors which correlated with career satisfaction and desire to stay in the job amongst hospital-based occupational therapists, physiotherapists and S-L Therapists, Barnes (as cited in Randolph, 2005) stated that the only significant positively correlating extrinsic factors were productivity expectations and a flexible work schedule (Randolph, 2005). Intrinsic factors that positively correlated with job satisfaction and desire to stay in the job were stable work environment, opportunity for professional growth, input into departmental decisions, and practising in an environment that was in line with the professional's values. Intrinsic factors that positively correlated with job satisfaction only, were opportunities for direct patient care, feeling competent, accomplishing career objectives, and meaningful work. Intrinsic factors that positively correlated with desire to stay in the job only were fair policies, and closeness with co-workers.

Harrison (1983, p. 224) stated "a sense of competence and a feeling of efficacy are the results of being able to affect the environment and meet its challenges". It has been proposed that significance is a core motive for all people, especially those engaged in a profession, and that people in the helping professions want to feel that they are making a difference in others' lives (Cherniss, 1995). Professionals may develop positive affective responses to their jobs if they believe that what they are doing is valuable and makes a difference to the lives of their patient(s).

Harrison's social competence model of burnout (1983, p. 224), although developed over twenty years ago, illustrates clearly the nature of transactions between the individual and his or her work environment. In relation to S-L Therapy and other healthcare professions, the model demonstrates that while the motivation to help and serve others is an important pre-requisite for the professional, the presence of supportive aspects (helping factors) significantly affect the professional's sense of competence and resultant motivational enhancement. Similarly, the presence of non-supportive aspects (barriers) significantly decreases the professional's sense of effectiveness, leading to burnout and a reduced motivation to help others.

Some cited supportive aspects include: participation in peer counselling and support from colleagues, feeling supported by managers, feeling training had prepared them for the working environment, feeling their expectations of the job had been satisfied, feeling a sense of pride and achievement when goals were attained, and experiencing work as interesting and rewarding (Akroyd, Wilson, Painter, \& Figuers, 1994; Collings \& Murray, 1996; Culbreth, Scarborough, Banks-Johnson, \& Solomon, 2005; Hasselkus \& Dickie, 1994; Jenkins, 1991; Jenkins \& Elliott, 2004; Kilfedder, Power, \& Wells, 2001; Lloyd, King, \& Chenoweth, 2002; Lloyd \& King, 2001; Moore, Cruikshank, \& Haas, 2006a; Moore, Cruikshank, \& Haas, 2006b; Reid et al., 1999; Um \& Harrison, 1998).

Non-supportive aspects (barriers) include high job demands and work overload; low supportive work relationships with supervisors and co-workers; dealing with death and dying; lack of essential resources; uncooperative family members and clients; time constraints; poor or unfair remuneration and disregard for professional worth (Austin, Shah, \& Muncer, 2005; Carson, Wood, White, \& Thomas, 1997; Cheng, Kawachi, Coakley, Schwart, \& Colditz, 2000; Decker, 1997; Lloyd \& King, 2001; McGibbon, 1997; Moore, et al., 2006a; Murray, 1998; Smith \& Nursten, 1998; Pope, Nel, \& Poggenpoel, 1998; van Wijk, 1997; Webster \& Hackett, 1999).

The literature has shown the multidimensional influences on S-L Therapy as a profession. It is a helping profession challenged by having to construct its identity in rapidly changing socio-political contexts, continuously shifting towards a social model, questioning its practice, and practitioners experiencing the same professional stress and burnout felt by other helping professionals. Despite the depth and breadth of the literature, the essence of the experience of being a S-L Therapist is an area which has not been sufficiently explored. This study explores the lived experience of the S-L Therapist, to contribute to the body of knowledge in this area.

\section{Methodology}

Aim

The aim of this study was to explore and describe the lived experience of being an S-L Therapist in the Western Cape public health service.

Research question: What is the lived experience of being an S-L Therapist in a rapidly changing public health service in the Western Cape?

Participant selection criteria

Participants were required to meet the following inclusion selection criteria:

- At least two years work experience as a S-L Therapist in the Western Cape public health service (hospital or community)

- Currently a full-time or part-time S-L Therapist in the Western Cape public health service (hospital or community)

- If on a dual register (S-L Therapy and Audiology), $50 \%$ of the participants' weekly activities had to be dedicated to S-L Therapy.

- Voluntary participation with openness to share experiences

Participants who were at different stages of their careers were selected as this was assumed to broaden the range of experience which might emerge during interviews (Patton, 2002).

Purposive sampling was used in order to select participants (Guba \& Lincoln, 1989; Schofield and Jamieson, 1999). Purposive sampling is appropriate for small studies as the "logic and power of purposive sampling lies in selecting information rich cases for study in depth" (Patton, 2002, p. 230).

The study was limited to the Western Cape as it was a context which was undergoing rapid change and there was a need to understand experiences within this context. The researcher also had close knowledge of the context which was a strength in an exploratory study of this nature. The study was limited to this area to allow the researcher ease of access 
to participants to enable personal communication.

Access to participants

Following approval from the University of Cape Town Faculty Research Ethics Committee, the medical superintendents and Speech Therapy heads of department of the three tertiary hospitals were contacted. Information about the study aims and what participation would involve for staff members was provided. Once permission was granted, all S-L Therapists in each hospital were individually e-mailed with the study information and participant requirements, and requested to respond indicating either willingness or unwillingness to participate. Each S-L Therapist who agreed to participate was contacted telephonically in order to arrange an interview time and venue. Participants were assured of confidentiality and of their right to withdraw from the study at any time without penalty or prejudice.

\section{Description of participants}

The sample group comprised seven female S-L Therapists ranging in age from 26 to 52 years with a mean age of 36 years. The number of years work experience ranged between 3 and 27 years, with three participants holding Bachelor degrees and four holding Masters degrees from two universities in Cape Town. All, at the time of data collection, worked at one of the three tertiary hospitals in the Western Cape. Five participants had dual registration as S-L Therapists and Audiologists while two had single S-L Therapy registration. Five of seven participants had a predominantly paediatric S-L Therapy caseload.

\section{Ethical considerations}

Ethical approval was obtained from the School of Health and Rehabilitation Sciences and the University of Cape Town Faculty Research Ethics Committees. Participation in the study was voluntary. S-L Therapists who declined to participate were not contacted again in connection with the study. Written informed consent was obtained from each participant.

Identifying information about the participating S-L Therapists was kept confidential and participants were allocated a number which appeared on all transcripts. Identifying information was removed from all direct quotes without changing the meaning of the words. As S-L Therapy departments in the Western Cape public service are small, all correspondence between the researcher and participant was conducted via personal e-mail which is password protected.

Issues in relation to interviewing colleagues

As the researcher is herself a S-L Therapist, and in view of the limited number of S-L Therapists working in the Western Cape public health service, it was not possible to eliminate all S-L Therapists known to the researcher from the potential pool of participants. Advantages of interviewing colleagues include shared language and shared level of education, norms, and knowledge of the participant workculture (Holloway \& Wheeler, 1996). A potential disadvantage, such as lack of trust and privacy between participating S-L Therapists and myself [the researcher], was minimised by avoiding face-to-face discussions with participating and non-participating S-L Therapists in the workplace and requesting that participants not discuss the content of their interview with fellow colleagues. The danger of me [the re- searcher and a S-L Therapist] becoming over-involved and over-identifying with the participating S-L Therapists was minimised by formally assuring the participant that I was conducting the study from the point of a researcher and not a S-L Therapist or colleague and that I would not be assuming or drawing on prior conversations we may have had. Continuous researcher self-reflection and bracketing (Creswell, 1998; Holloway \& Wheeler, 1996) of presuppositions and attitudes, and ongoing discussion between the researcher and study supervisor contributed to maintaining the integrity of the research process.

\section{Research Procedure}

\section{Data collection}

Data were generated through seven individual in-depth interviews (approximately 90 minutes in length); the keeping of field notes and reflective memoranda by the researcher; and seven follow-up interviews (approximately $30 \mathrm{~min}-$ utes in length) to discuss preliminary study findings.

Each interview commenced with an initial question "I would like you to tell me as fully as you are able, and drawing from your experience, what it is like to be a S-L Therapist in the public health service?"This question was followed with explorative questions and reflective responses by the researcher. Phenomenological interviewing relies on skilled listening without prejudice by the interviewer, and encouraging and allowing the interviewee to describe their experience without interruption by questions from the interviewer. As the participant is actively involved in the gathering process of discovery and interpretation (van Manen, 1990, p. 98), and with interpretation taking place during and after the formal data gathering phase, interviews deliberately did not contain a set of pre-formulated questions. This allowed the researcher to remain open to new and unexpected views and ideas.

Bracketing (Creswell, 1998; Holloway \& Wheeler 1996) was applied whereby the researcher's beliefs about the phenomenon were made explicit and temporarily suspended, enabling the researcher to be open to new understandings. Interviews were recorded, dated and labelled with the participant's number, and transcribed verbatim to reliably reflect the interviewee's precise words including non-verbal and para-linguistic communication (Hycner, 1985).

Interviews were followed by the writing of field notes which captured the "flavour of the interview" (Holloway $\&$ Wheeler, 1996, p. 70) as well as participants' behaviours, at-, titudes and non-verbal information (Mason, 1996). Reflective memoranda were not part of the direct data collection process, but contributed to the analysis phase and enhanced rigour by describing the research process and capturing the researcher's views, thoughts, feelings and opinions. Individual follow-up conversations were held with each participant to clarify issues which were not clear in the original interview.

\section{Data Analysis}

The challenge of qualitative data analysis is "making sense of massive amounts of data, reducing the volume of raw information, identifying significant patterns, and constructing a framework of communicating the essence of what the data reveal" (Patton, 2002, p. 432). The analytic frameworks suggested by Colaizzi (1978) and Hycner (1985) were followed 
to analyse the verbatim transcriptions.

The researcher read each transcript a number of times and significant statements relating to the phenomenon were extracted. These were tabulated in an adjacent column with the statement re-written in the third person, which helped to personalise the statement (Table 1). Duplicate statements were eliminated. Next, each significant statement was coded to bring out the meaning in the description (Table 2). Next, similar codes within each transcript were grouped together into clusters. Clusters were grouped across all transcripts into categories which were finally assigned to one of five final themes. Themes and categories were checked against each original transcript to ensure that all information from the transcript was contained in the themes and vice versa. Findings from each theme were written as an exhaustive thick description in paragraph form substantiating the analysis through the use of interview excerpts. van Manen (1990) describes the identified themes as being "objects for further reflection in follow-up hermeneutic conversations in which both the researcher and the interviewee collaborate" (p. 99). This was achieved by returning the themes and a short description of each to the participants to read, and then conducting a $30-40$ minute discussion where each participant was given the opportunity to comment on the findings, clarify issues and expand on the interpretation. Lastly, findings from all five themes were combined into an exhaustive description of the phenomenon.

\section{Rigour and Trustworthiness}

In qualitative inquiry the credibility and legitimacy of the study is dealt with under the broad framework of trustworthiness (Patton, 2002). Credibility (in preference to internal validity) refers to the truthfulness and value of the researcher's findings to represent the world as perceived by the participants (Maxwell \& Satake, 2006). The researcher has provided a clear description of the study setting and participants, the research process as well as describing the researcher's personal experience of being a S-L Therapist. Shenton (2004) recommends the "development of early familiarity with the culture of participating organisations before data collection takes place" (p. 64). As a S-L therapist, the researcher was familiar with the settings and facilities in which S-L therapist participants worked. Shenton (2004) offers further strategies for enhancing credibility: potential participants should be given the opportunity to refuse to participate, contending that this ensures that data are obtained only from participants who are genuinely willing to take part in the study; frequent debriefing sessions between researcher and superiors/supervisors; peer scrutiny by colleagues, peer and academics; member checks (achieved by revisiting the participants after their interview to validate that the emerging categories and themes were consistent with the participants' experiences); researcher's reflective commentary, and thick description of the phenomenon under scrutiny, all of which were adhered to in this study.

Applicability/transferability is the degree to which the findings can be applied to other contexts, groups or generalised to the greater population although generalisability is not relevant in many qualitative research projects (Krefting, 1991). "The results of a qualitative study must be understood within the context of the particular characteristics of the organisation and perhaps the geographical area in which the fieldwork was conducted" (Shenton, 2004, p. 70). Participants with a range of career experience were selected to facilitate transferability judgments on the part of S-L Therapists in other public service settings (Guba \& Lincoln, 1989).

Confirmability (in preference to objectivity) shows that data are linked to their sources (Guba \& Lincoln, 1989; Holloway \& Wheeler, 1996). An audit trail was used to enable the reader to understand and evaluate how methodological, analytical and theoretical decisions were made (Lincoln \& Guba, 1985), thus ascertaining whether the findings are "grounded in the data" (Lincoln \& Guba, 1985, p. 323). In this study the researcher kept reflective memoranda of ideas, thoughts, feelings, opinions and difficulties experienced, e.g. the researcher's feelings during and following interviews. Included was additional information about the participants themselves such as reactions to events and comments made. Following transcription of each interview, the researcher's impression of that participant's experience along with the researcher's knowledge of that participant as a colleague was noted. This assisted to bracket out personal feelings in respect of knowing some participants as colleagues. After each stage of analysis progress notes were made and tables of preliminary findings stored for comparison to the following stage findings. This also contributed to the dependability (reliability) of the research process and the findings.

\section{Findings}

Phenomenological analysis across all interview transcripts resulted in five themes that represent the lived experience of being a public health service S-L Therapist. Each theme is supported by excerpts from participants' interviews as quotes (in italics) which serve as exemplars of the participants' experience.

Theme one: Expectations of practice and practice realities

S-L Therapists begin their careers with the desire to make a significant difference to the lives of their patients. They are motivated because "you're concerned about their speech and language":

"...I think, sort of wanting to be able to, to belp people, um, you know an underlying desire to, to be able to try and make a difference somewhere .... you know we want to be able to, to belp everyone make a big difference, make their lives better and, belp them to cope at school and belp them to, be a success in life, and make their social circumstances easier..."

Working as an S-L Therapist is different to their anticipations and they soon realise that they are not able to help everyone they see. Furthermore, they feel let down as the public health system is not as organised and efficient as it was portrayed during their training, and they struggle to gain the same level of control they had as student therapists:

"...I think in, in the beginning it's a bit harder 'cos you, you come in into the profession and it's very different to what you were prepared for as a student. As a student, I mean everything is like in order and you know it looks like there's this whole system in place to deal with people coming in with speech problems, with bearing problems and you know every- 


\section{JOCELYN A. WARDEN, PATRICIA MAYERS AND HARSHA KATHARD}

thing looks good on paper, but when you actually start, start working...it's a lot messier than what I think you expect and I think that is a bit of a, a let down in a way, um, and a bit frustrating..."

The abovementioned progression is described by Tryssenaar and Perkins (2001, p. 22) as the "transition stage" which is an eager "marking time" through a student's final months in training; the "euphoria and angst stage" as the therapist begins professional practice with both excitement and trepidation; the "reality of practice stage" where therapists struggle through sometimes "unpleasant experiences" (p. 22) as S-L Therapists come to terms with the realities of the job.

Research conducted with health, welfare and education professionals has identified issues consistent with the experiences of current study participants. Curtis and Martin (1993) reported physiotherapy graduates as having had "unrealistic expectations" (p. 588) on leaving student life and entering the professional world. Expectations were not always met or were met in an unanticipated fashion. Lloyd et al. (2002) reported that social workers have felt dissatisfied with the discrepancy between the ideals of social work they were trained in and the reality of day to day practice; participants stated that their profession "has a very idealistic and reforming philosophy which is not met by many social workers in practice" (p. 262).

In a study by Madjar, McMillan, Sharke, and Cadd (as cited in Chang \& Hancock, 2003, p. 156) nurses stated that they experienced a significant gap between the theory they had learned in training and what was expected of them in practice. School counsellors have been reported to experience a discrepancy between the ideal role and the role that interns (novice teachers) experience in practice (Culbreth et al., 2005). A current study participant described defining her role is a "continuous challenge".

Communication disorders are seldom as clearly diagnosed and treated as many medical conditions, and the nature of these disorders is such that a complete recovery following intervention is often not possible or realistic. Residual deficits may remain, and this may leave S- $\mathrm{L}$ Therapists feeling that their work is unfinished, unresolved and incomplete: "the nature of language disorders, never, never fixed, seldom, it's, it's a life-long disability..."

Patients who attend the public service healthcare facility are mainly those with no medical insurance who often live in negative social contexts. For S-L Therapists this "perpetuates the current situation" and is a barrier to progress. There are aspects of S-L Therapists' interventions which cannot be implemented without societal change:

"...but sometimes the bitterness around the edge ja [yes], definitely, I guess that would kind of represent the aspects of society that are beyond me as an individual to effect any change..."

To counteract these limitations, S-L Therapists acknowledge the pressures their patients face and seek to use their skills and knowledge to "belp people [patients] to understand how they [social elements] are related to the language problem". Through examining the environmental stressors at play in a patient's life, S-L Therapists attempt to understand fully the patient's language/speech difficulty. They dedicate their time and energy to empowering and educating their patients and families about the role they can play in bringing about lasting change in their own lives and cope with future challenges in a positive manner.

"...um, but I think ultimately if things in their home situation or community situation are affecting the specific speech and language difficulty, one needs to address them otherwise dealing with the underlying speech and language disability can be a bit of a waste of time..."

Over time, as S-L Therapists come to terms with the realisation that there is much that is beyond their personal capacity to change, they become less idealistic and more pragmatic about what they can and cannot achieve. They begin to establish more realistic goals and expectations, adapting their therapy to the setting and patients:

"...I'm just more realistic in my goals, and my expectations, um, and I'm more realistic about the population I work with, um, what they can, what, what I can expect them to want to do... I mean you know when you're 20, you think you can change the world, now I know I can just change my corner of the world! so that's fine!..."

Acceptance of this reality enables S-L Therapists to become more realistic about future experiences. By being less idealistic about their work, their patients and therapeutic outcome, S-L Therapists experience less anxiety about needing to " $f x$ " every patient's problem. No longer solely responsible for every patient's progress, and free from idealistic expectations, S-L Therapists are better able to deal with difficulties which arise and view them as being part of the job rather than crises. This adjustment to their profession is described by Tryssenaar and Perkins (2001, p. 22) as the "adaption stage" which is the last of four distinct chronologic stages experienced by new therapists, marking the beginning of their "new world of professional practice" (p. 22).

Theme two: Being part of the "underdog" profession: role definition and status

A great frustration for S-L Therapists' is public and fellow health professionals' misperceptions of the profession and the nature of their work. They feel that these attitudes and beliefs are uninformed; this makes them feel underestimated and underrated as professionals, as they know and understand their work to be far more complex and intricate than commonly understood:

"...ja, [yes] there's always the perception that you, you work mostly with children, that you work in a school...that you work with stutterers... they're not aware of the diverse range in age groups that we see, I mean the diverse range of disorders and age groups, and um, $j a$ [yes] types of things that we deal with..."

Although the multidisciplinary team approach is a principle to which health professionals subscribe, S-L Therapists often feel devalued as professionals, discouraged, disillusioned and not consistently recognised as equal members of the team:

"...I think there's a certain amount of frustration because I think the general lack of knowledge of Speech Therapy as a profession in a community and especially at, you know at a community bealth level, nurses and doctors and other professionals I think are often not fully aware of what our role is - what we do - who we see, um why we see them - what can 
offer, you know all those types of things... so there just isn't a lot of knowledge about Speech Therapy..."

In a study which explored how social workers experience their work, participants stated that their role is misinterpreted as "just being nice or doing the common sense things that anyone can do" (Dillon, as cited in Lloyd et al., 2002, p. 257). Occupational therapists have also reported feeling "devalued" (Hasselkus \& Dickie, 1994, p. 147) and having their skills "unused" (p. 147) or "blocked" (p. 147) by certain team members. Current study participants described similar experiences, in that talking and swallowing are viewed as automatic processes that everyone can do, and are less of a priority than other more obvious impairments. This is itlustrated in the words of one participant who said "for many of them, [stroke patients] it is about getting back to walking... sometimes much more than communication". The specific experience of having a skill "devalued" or "blocked" is reflected on by a participant in the current study. She related an often-repeated situation in which a decision regarding placement in a rehabilitation hospital seldom takes into consideration the opinion of the S-L Therapist. Her experience was that, should a stroke survivor be left with both a physical and communication deficit, rehabilitation would immediately be recommended, however if left only with a communication difficulty, the referral to rehabilitation would not be automatic. Even after strong motivation, her opinion is usually disregarded, leaving her feeling disrespected as a professional.

Participants suggested that contributory factors to these misperceptions is the abstract nature of the disorders treated by S-L Therapists, the invisibility of communication disorders as compared with physical diseases, the historical lack of advocacy by S-L Therapists and the relatively low status of people with communication difficulties in many communities:

"...speech and communication disorders are not as concrete or as visible as more physical disorders, as treated by a Physio [physiotherapist] or an Occupational Therapist, um, you know if someone's got a, had a stroke and one side of their body is weak, you'can automatically see it, um, whereas speech and language is, not as visible..."

"...people with communication difficulties as I prefer to call them whatever they are, whatever their nature, is that because these difficulties are not visible, they're not well understood um, people, the public think that people who can't communicate properly are stupid are worthless are um, they become the butt-end of jokes..."

Continually having to explain what S-L Therapists' work entails and the nature of their role is exhausting. A further frustration is being referred to as an elocution coach or "someone who helps people to speak well". The ignorance surrounding the profession is such that one study participant stated that she felt that it would have been much easier to have chosen a different career. The relative invisibility of speech, language and communication disorders means the difficulty is not well understood or acknowledged. Even within the subset of patients with different communication disorders, S-L Therapists are frustrated that more visible difficulties are prioritised. A patient is only likely to seek the S-L Therapist's help for a communication problem that is negatively affecting his or her occupation or quality of life. It is hard to accept the relative complacency of persons with a communication difficulty; as many are content to tolerate it as long as it does not interfere too much, thus seldom seek help in the early stage of the disorder.

Patients with communication problems are also misunderstood. One participant described her experience: "the lay person's attitude to people with communication disorders is one of ridicule" and that in her work she has often been "a recipient of the casualties of the lay person's attitude and actions towards them". Patients may have explored numerous options before accessing the Speech Therapy services and have often endured teasing and ridicule.

S-L Therapists experience their work environment as nurturing, a unique community which is almost "like bome" which is contrary to the perceptions of the public regarding state hospitals:

"...ja [yes], I think they, people just don't have any idea of this context even that you're working in or you know it, it, $I$ think this hospital, it's like a little world on it's own, sort of a community in a way and $j a$ [yes], if you haven't been bere you don't quite understand what its like..."

S-L Therapists experience feeling secure and being nurtured by their environment which makes the tension between their experience and the public's misperceptions difficult to reconcile:

"...people just come in bere, they see the, the dirt, everything peeling off the walls, the whatever!... the first impressions here are not very positive I think for many people ja [yes]......ja [yes], but it's a bome away from home sometimes in a way [laughs] now.... I think it's, it's, if you've been bere a long time, one, you, you know how things work bere, so I think that's just a negative perception we really have..."

Unlike physiotherapy, occupational therapy and social work, S-L Therapy services are under-represented at community health facility level, secondary hospital level and in mainstream education. As a result, patients' only options are to access S-L Therapy services at a tertiary level even if it is geographically and logistically very difficult to do so:

"... often clients can receive the medical belp they need at a community level, but not the rehab at a community level..."

"... and I think that's, that's an area of, where our profession really needs to be to be working at is at a level of, um...communities, but also educators, doctors..."

Within the Western Cape, the hospitals with skilled and available medical personnel are geographically some distance from the majority of their patients. This negatively affects patient attendance and increases $S-L$ Therapists' frustration. While certain $S-L$ Therapy services require medical support which is offered by the hospital, a large proportion of the services S-L Therapists offer to both adults and children are not suited to this setting and would be "far more effective if offered at a community level or in mainstream classrooms". S-L Therapists are left feeling detached from their patients and misplaced as health professionals who provide decontextualised services.

The lack of S-L Therapy services at community level exacerbates the pressure to get through the large case load in a limited time, which, when added to the associated administration, can result in reduced productivity and less time and 
energy to focus on each individual patient. The lack of sufficient time for patient care is a consistent finding in other human service profession research. Occupational therapists are reported to feel unable to serve clients adequately when coping with a large caseload (Hasselkus \& Dickie, 1994) and to experience excessive paperwork and statistics as a major source of stress (Bailey, 1990; Freda, 1992; Pringle, 1996). The physiotherapy literature reveals similar findings in that "during periods of high demand for physical therapy" (Deckard \& Present, 1989, p.116) therapists felt pressured and complained about inadequate time in which to provide all their patients with adequate treatment. Physiotherapists in the above study reported feeling "torn between providing service to everyone" (p. 116) which decreased the quality of care and amount of time they were able to devote to each treatment.

\section{Theme three: Being connected}

$S-L$ Therapists engage in a broad range of relationships with others. Intervention is a collaborative process between S-L Therapists and patients and their families and involves "a tremendous amount of give and take". They place the patients and their families at the centre of the intervention process, giving them permission "to state their priorities and expectations of therapy". S-L Therapists recognise them as important and useful resources for change and strategically look at what their patients and families are able to contribute to the treatment/rehabilitation process.

S-L Therapists' relationships with their patients are complex and interactive (Holland, 2001). Current study participants described a real sense of connectedness to their patients as they are intimately involved in a dynamic two-way helping relationship fuelled by a desire to help, remediate and improve the presenting communication or swallowing difficulty. Worrall \& Frattali (2000) described S-L Therapists' involvement with their patients as "entering into people's lives in a very real way and becoming involved in issues of human living" (p. 193). All therapeutic endeavours occur in cultural context with cultural factors demanding awareness and sensitivity (Holland, 2001).

The importance of personal relationships is reflected in a person's choice to enter the profession of S-L Therapy, for which helping other people is a primary motivation (Byng et al., 2002). In line with the abovementioned two-way helping relationship, Egan (2002, p. 7) presents two principal goals of helping: the first being to help clients manage their problems in living more effectively and develop unused resources and missed opportunities more fully; and the second being to help clients become better at helping themselves in their everyday lives. He further states that due to the nature of helping others, helpers "are only successful to the degree to which their clients, through the client-helper interaction are better able to manage specific problems and - develop specific unused resources and missed opportunities more effectively" (p. 7).

Collaborative partnerships with the healthcare team help $\mathrm{S}-\mathrm{L}$ Therapists offer more effective and holistic management and reduces the pressure and expectation that they feel to try to meet all their patients' needs:

"... when we run multidisciplinary clinics we provide a much better service for a patient because it's one-stop-shop, it's less time for them, it's less schlepping [walking] around less waiting, less stress... everyone's in one place, so that we work together at the same time with the parent and the child and we can give them feedback together and we have one plan... which is just a more efficient way of doing things..."

In the hospital setting, patients often require interventions in addition to that offered by S-L Therapists. The multidisciplinary team is a source of information and support. This illustrates the team's role in producing better quality service and comprehensive approach than its individual members working as solo practitioners. The professional is able to increase productivity and has a sense of accomplishment (Benierakis, 1995). Current study participants described experiencing great willingness from team members to work collaboratively, making their own work day more enjoyable. This is consistent with a study of occupational therapists who reported that job satisfaction is derived from being part of a multidisciplinary team and that good communication and co-operation among team members increased their sense of fulfilment (de Wesley \& Clemson, 1992).

Despite this positive experience of teamwork, ignorance and misperceptions about S-L Therapists' professional roles continue to exist among colleagues. Study participants described feeling "side-lined" compared to professionals from seemingly better-understood professions, and described not being recognised as equal members of the team. For one participant in particular, remarks and actions of medical doctors in particular make her feel "stupid" and that her intervention techniques are not sufficiently academic. An Australian study in the occupational therapy profession found that the underlying ignorance and misperception of the profession is seen in both an absence of referrals or inappropriate referrals to the profession (Moore et al., 2006a).

Current study participants spoke of poor collaboration with some educators, certain healthcare professionals, and some privately employed S-L therapists. This makes effective management very difficult and creates a barrier for the development and maintenance of good working relationships:

"... we do get quite a lot of negative comments, it's, it's, especially (name) and I who've been bere for many years, um, you go to any gathering of therapists and they say "oh, you're still at (name) - shame!" and it's kind of like 'can't you do anything better for yourselves, that you, you're still landed bere. I think that the perception is that you start off in the public sector when you don't know very much, to learn and, which is true to a certain extent, it is a very good place to start but, um, it's almost the perception that perbaps you graduate to private practice!..."

Theme four: The holistic nature of the Speech-Language Therapist's practice

The therapy process involves much more than direct therapeutic intervention. S-L Therapists need to consciously engage with their patients in order to better understand their needs. They need to "...really get to know them beyond the superficial level, to just go a bit deeper... but it's also about bearing them, it's about having the bumility to bear them without judging them..."

S-L Therapists focus on more than the presenting communication disorder and take a holistic approach to patients 
and families, placing high value on the way their patients use speech and language functions, rather than individual grammatical structures, to gain communicative power. The aim is to assist their patients to use language as a tool for everyday life and to facilitate successful social integration:

"...I mean I think one of the most important things is not only focussing on sort of specific language things but looking at more lifestyle communication and pragmatic skills which are going to belp them later on in life as opposed to being able to say something that's syntactically correct! or whatever, and you know it might be more of a priority to deal with, get them coping at a certain level which is functionally going to be useful for them as opposed to what would be perbaps ideal..."

The presence of a communication difficulty is the reason for the consultation, yet S-L Therapists' primary focus is on the 'person' and their role requires that they consciously address their patients' salient needs with the same respect and rapidity as they do their communication difficulty:

"... it feels like you're giving more than just that [therapy]... but you end up having to, to just make, make their lives neat and tidy from other aspects so you can actually - you know, if all that is in a mess then somebow the therapy is not, they can't focus on therapy because they too stressed about blab blab blab and something else, so it's almost like you have to focus on all the little bits and pieces as part of like a like a holistic sort of management that you're doing..."

S-L Therapists understand how speech and language are used in the daily interactions between their patients, their patients' significant others and community, and the severely limiting impact of the communication difficulty on their patient's ability to interact effectively with his or her world:

"... speech and language is a part of interaction which is a part of the child's family, which is a part of their society..."

There are times when S-L Therapists' roles entail not doing anything, but just being there for their patients and consciously assuming the role of supporter, advisor, or counsellor. One participant described how she regards herself as a committed friend and support to her patients and families, needing to operate from a place of "enormous empathy".

"...just to be supportive, I think it's kind of to acknowledge what you're feeling, it is a process, it does take time... and certainly with my adults if I cry with them, I just think it adds a dimension, they do know that you feel, and why should I bide it? If I'm going to cry and fall apart and I can't help him, that's a different story, but if you're belping bim and feeling for bim..."

S-L Therapists make personal investments into the lives of their patients and families by offering themselves and their skills in the therapeutic process, with their own needs subservient to the greater needs of their patients. They are fully present in sessions with their patients and consciously focus their minds, thoughts, attention and energy during that time, not allowing themselves to become distracted:

"... you know you bave to give them everything, you know your all... if like I assess a child I'm not gonna, my whole heart is there $O K$, type of thing, it's not $O K$, I'm doing this but my mind is somewhere else, I don't know, I mean... you can't be...you are going to try to put $110 \%$ in so no matter bow busy your day is, no matter what's happened before, no matter what's coming, you bave to, you just put on your ther- apist's bat and off you go...it's like, you know a child comes running, smiling and you've got to, you've just pull out what you need and you know deliver the goods!... and sometimes that's a natural thing, other times you dig deep!..."

The therapeutic process involves more than specific activities; there is an emotional component to the therapy. Helping professions such as S-L Therapy involve more than just helping, but require "an investment of knowledge and skill blended with facilitating interpersonal qualities to effect change in another individual" (Lubinski \& Frattali, 2001, p. 189). Regardless of personal feelings and circumstances and day-to-day pressures, participants described how the patient always comes first. S-L Therapists are emotionally drained after a day of making such intense investments into the lives of their patients. A day at work is described by one participant as "much more than just a job". The responsibility of managing patients with serious communication difficulties is onerous. The management of even uncomplicated patients is like "trying to eat spaghetti" in that it is "bard to manage". As they interact with their patients on a deeper level, an emotional bond develops with expectations of them as therapists:

"... they come to you with all this hope and I think because we are in a profession that gives people a little more time - it's not you know quick consultations, they bave a lot of one on one time with you and because it's - it's not just so medical but so - therapeutic - there's a lot of counselling and stiff that goes on, that, I think it doesn't just affect the patient, you know somehow you also become involved, in their lives..., in what it means for them... you know it becomes your, your problem as well..."

S-L Therapists share in the emotional journey of their patients and families. One study participant described how in the past she had "boped with the family" that test results would not return as suspected. Other participants described the emotional journeys they have taken with patients and families as together they express grief and disappointment at the birth of a disabled child, the diagnosis of a terminal illness or life-altering procedure. Taking on the responsibility of managing patients with serious medical conditions and chronic disabilities requires emotional maturity and stamina. One participant described her experiences as requiring "staying power which takes more maturity than your years".

The repeated exposure to illness and suffering can make S-L Therapists hardened, no longer as sensitive as they were to the shocking reality of their first experience. Certain sights, sounds and smells become so much a part of their daily activities that they no longer have the impact they once did. They easily lose their sense of what is regarded as normal, see disorders as the norm, and thus seldom expect anything more. They lose hope that miracles do happen and that recoveries can occur. S-L Therapists may find themselves approaching their patients from the perspective of "deficit", thinking only about what they cannot do, instead of what they are still able to do:

"... I mean I remember when I was a student, just seeing pictures of children with cleft lip and palate thinking this is terrible, I mean now you think 'oh is that all that's wrong with you!' 'ob, that'll be fixed, I mean the brain's working fine' and you've seen people with so much worse than that that your, you sort of rate 


\section{JOCELYN A. WARDEN, PATRICIA MAYERS AND HARSHA KATHARD}

your degree of how bad something is..."

Healthcare professional [S-L Therapists] have have to deal with occupational stressors that are not part of most other occupations in that they deal with people in situations involving death and suffering that have a profound effect on them (Payne \& Frith-Cozen, 1987). For this group of SL Therapists, the repeated exposure to illness and suffering with the common sights, sounds and smells makes it easy to become hardened to seeing people suffer "with even the most experienced professional feeling awkward and helpless" (Arbore, Katz, Therese \& Johnson, 2006, p. 17). Seeing disorders as the norm and seldom expecting anything more was also described by Arbore et al. (2006, p. 25) who state that in such cases, the professional is often left to feel that there is nothing he or she can do for the patient except to $b e$ with the patient in the situation. Health professionals react in different ways to seemingly hopeless situations. They either become over- or under involved, which is described as unconscious countertransference feelings (Arbore, et al., 2006 , p. 22). One participant described her shock and surprise at patients who, against all odds, make unbelievable recoveries. This makes her aware of how pragmatic and matter-of-fact she has become.

Theme five: Erosion or promotion

The public service setting presents many challenges for S-L Therapists: time pressure to complete their work, high patient caseloads, time-consuming reports, insufficient staff complement, changes in promotional possibilities (the abolishment of rank promotion based on work experience) and no financial incentives other than their monthly salary:

"... and I think that especially being in the public service where there's more, there's more of a rush to get things done, um, there's numbers that you bave to get through, there's waiting lists... I think if there was time you could sort it out better, um, but you in a bit of a burry too, to sort out all the loose ends sort of move on so it does, I think the time and the pressure on, on numbers and things like that does, does affect bow much you can actually do..."

"...now money's an issue, but in the past the salaries were adequate um, as the cost of living increased so the salaries didn't keep pace, but in the beginning it wasn't as shocking a salary as it is now..."

A large caseload results in less time and energy to focus on each individual patient, especially with the time-consuming referrals and report writing: "I think it also depends on your, your workload um, I think if you're really working bard you bave less of that for each patient..."

Despite the many challenges which make S-L Therapists question their decision to stay in the public service, this is countered by the predictability and security they experience in this setting. A guaranteed stable salary and benefits, reasonable administrative support and a high level of predictability in the nature of their work makes them feel settled, grounded and in control:

“...I mean I've always had a job, I'm, I'm in quite a secure environment, which is maybe also why I'm staying bere you reach a point where you, actually it's too comfortable maybe to [both laugh], to move on now ja [yes], also ja [yes], my career has been fairly safe ground for me..."

"...the benefits of staying bere, of staying bere have been big- ger than, the benefits of, of private sector..."

S-L Therapists receive consistent and predictable administrative support which enables them to focus on service delivery rather than on administrative duties. Their familiarity with the way their environment functions, whether positive or negative, defuses much of their frustration over everyday challenges. They are prepared for the common challenges of a public health service and able to manage these.

Security, permanence of employment, regular salary, pension benefits, together with, flexibility of vacation leave and clearly defined sick leave benefits contribute towards the stability of their roles. Similar findings were reported in the responses of participants from a study of Occupational Therapists working in the British National Health System who stated that they regarded themselves as having a job "for life" and reported valuing their pension and good conditions of service (Pringle, 1996, p. 405).

The diversity of S-L Therapists' caseloads provides them with opportunities to grow and develop as therapists. This enables inexperienced therapists to develop a sound clinical foundation as they work in the tertiary service infrastructure and support networks. One participant described how the freedom she had to "find ber feet" is rarely available in other settings, in which providing services to paying clients is the priority:

"...Initially you're pretty much finding your feet in the profession, you're doing, a little bit of everything, figuring out what you like, what you do better, what you don't do so well, so there's that initial kind of just almost testing the waters kind of thing..."

Working in a training hospital offers S-L Therapists varied patient exposure and the opportunity to manage patients with a wide variety of communication disorders including those with multiple and / or rare conditions. This makes S-L Therapists' experiences dynamic, stimulating and challenging. It stretches them in terms of the knowledge, clinical skills and expertise they require and demands flexibility, creativity and a sound knowledge and understanding of different treatment approaches. The three tertiary hospitals! in this study are teaching hospitals, with the ethos of learning, teaching, research and clinical advancement. They have access to academic resources and staff which offers them educational and clinical development opportunities. The teaching environment is stimulating, rewarding, and a source of significant job satisfaction.

This expectation of exposure to valuable learning opportunities in specific contexts is common to other health professions. In a study looking at career choice, 55 percent of newly qualified Canadian physiotherapists reported having chosen a public service hospital setting due to the perceived learning opportunities and the anticipation of it being an appropriate environment to start as a novice therapist (Ohman, Solomon, \& Finch, 2002). In another study novice physiotherapists chose the hospital setting because of the learning opportunities they believed it would offer them (Miller, Solomon, Giacomini, \& Abelson, 2005). The hospital setting, which facilitated the grounding of their clinical experience, was viewed as a "stepping stone" (p. 148) to other practice settings. This viewpoint was not described by current study participants; rather it was their belief that this 
was the opinion of S-L Therapists in private practice. Study participants described privately-employed S-L Therapists to most definitely have the perception that "you start off in the public sector when you don't know very much, learn as it's a very good place to start, and then graduate to private practicel".

Even after many years of working in the public service health setting, the opportunities that initially attracted S-L Therapists to the public service continue to keep them motivated to stay:

"...um, and I think that's also especially if you work in the public sector, I don't know if it's more so, that you can do that, whereas privately you kind of working kind of for yourself whereas here you know you're working in the public sector, you're doing your bit for the community, um, you're working, you know there's, there's a bigger, you know there's a bigger picture type of thing..."

S-L Therapists who are socially motivated to work in this setting or who chose it because of the role they wished to play in this context, experience it very differently to S-L Therapists who did not have these same sentiments. Even after years in this setting, those who described themselves to have "chosen it" are still committed to the public service.

Despite the ups and downs of S-L Therapists' clinical work, the positive experiences and job satisfaction play a major role in their decisions to be a part of the service:

"... generally I can speak very positively about the, the public sector, and at the end of the day I choose to be here..."

S-L Therapists feel enriched by being exposed to the wide variety of people around them and have learned to accept others more, judge them less, and understand them more deeply. Engaging with patients and families on a daily basis requires them to go beyond a superficial level to "knowing where they're coming from" and "really understand the people you're working with". The daily interaction with people from diverse cultural and socio-economic groups enriches and deepens their understanding of humanity:

"... ff I hadn't worked here, I would never bave known much, as much about people who are not different, I mean we're all the same basically, live in different circumstances, have grown up differently, got different priorities perbaps um, I think it's made me more tolerant of people, more understanding of different ja [yes], just of different belief systems and culture..."

Being a part of their patients' journeys towards recovery and rehabilitation is an enriching and validating experience. There is a sense of accomplishment as they see their patients become empowered to succeed beyond the therapy setting. Victory for a patient is translated into renewed passion for what S-L Therapists do and why they do it:

“...I love it when I have a 'happy client'. When I've been able to make a difference...

...my patients actually, because of the, the, the type of patients I see, I'm humbled by them, I'm; they, they, they make me feel good on a daily basis..."

S-L Therapists' patients' successes are a personal victory, not because of the role they have played, but due to the deep connection they feel to their patients and their rehabilitative journeys:

"... Yes, obviously, I mean getting, um, being successful or getting something right, or making some, making a difference in, in a patient's life, it, yes, it reaffirms you and it makes you feel, ok yes you want to do this again, you are making a difference..."

S-L Therapists in this setting are greatly affected by their patients. Two participants expressed their feelings: "I love my patients", "I love working with them" and "I have had wonderful experiences with patients". Working and interacting with them on a daily basis humbles the S-L Therapist. S-L Therapists' experiences of crying with patients, talking about their progress, how they have grown, or being thanked for help they have given, are all rewarding and affirming experiences. A study investigating the satisfaction of occupational therapists (Moore et al., 2006a) reported that patient contact and working with patients was a highly fulfilling part of their work. One participant stated, "I don't think there's anything I'd rather be doing" (p. 22). Other participants described their relationships with patients as being meaningful and rewarding. Current study participants described feeling humbled by, and privileged to listen to the life stories and experiences of their patients, their past experiences and thoughts of the future. As S-L Therapists' patients share their experiences, their dreams, fears and reflections, therapists feel honoured that they choose to allow them to enter their reality. S-L Therapists feel enriched and validated as they realise the contribution they have made in their patients' journeys. Social workers, nurses and occupational therapists reported the opportunity to develop relationships with patients and see them progress as being a frequent source of satisfaction (Reid et al., 1999). For a current study participant, seeing patient achievements renew her passion for her work. S-L Therapists experience patients' successes as almost a personal victory, not because of the role they played in it, but because of the deep connection they feel to their patients and their rehabilitative journeys. An occupational therapist stated, in a study by Moore, et al. (2006a), how the role she is able to play in a patient's life gives her a sense of achievement and validates her as a person. S-L Therapists describe their relationship with patients as being full of "ups and downs", being as joyful and fulfilling as limiting and challenging and as "leading them to unexpected places" (Byng et al., 2000, p. 93).

\section{Limitations of the Study}

The researcher is a S-L Therapist at one of the tertiary hospitals from which participants in the study were drawn. Although there is a risk of over-involvement and over-identification, especially in the interviewing phase, studying colleagues is also viewed as an advantage (Holloway \&Wheeler, 1996). Qualitative research calls for the researcher to "immerse and involve him or herself in the setting and the culture under study" (Holloway \&Wheeler, 1996, p. 3) and to have a "close" (p. 3) relationship with participants. In order to minimise this limitation, the researcher kept reflective memoranda throughout the process and tried as far as possible to ask participants for clarification of their ideas and not assume to have a full understanding of what participants said before clarifying it with them.

A criticism of qualitative research is that studies with small samples (such as this one) prevent the research from being generalisable to the general population. From the outset current findings were not anticipated to be generalisable. The nature of the clinical work and the predominance of paediatric S-L Therapists in the study may mean that the 
experiences of S-L Therapists who work in other fields may not be fully described. The present study findings reflect the description and analysis of a reality experienced by S$\mathrm{L}$ Therapists in this specific setting, taking into account the conditions and context.

\section{Recommendations}

The absence of S-L Therapy services at community health centre level is a significant barrier to the provision of services to people who most require these. Speech Therapy departments from established hospitals should consider initiating outreach projects in the community i.e. district hospitals. Partnering with, and developing a good relationship with an outreach site, offers the opportunity to develop a much needed service and could lead to the establishment of a permanent service, in line with the objectives of the Healthcare 2010 plan for the Western Cape public service.

Participants' perceptions of the public's appreciation of professional role and function of the S-L Therapist have highlighted the need for further development. Marketing strategies which are sustainable and adequately portray the benefits of S-L Therapy and services need to be considered. For S-L Therapists working with children in particular, there is a need to strengthen relationships and referral between educators and S-L Therapists. Outreach programmes and information sessions to schools could facilitate this.

The education and training of S-L Therapists requires continual curriculum development to prepare and support new therapists in their role in a rapidly changing health service. S-L Therapists will need to be pro-active, market their profession, lobby for the development of appropriate, affordable and accessible services for underserved communities, and be creative in offering these within the budgetary constraints of the public health service.

\section{Conclusion}

This study has explicated the lived experience of being a S-L Therapist in the public service health setting, in a inquiry in which there is minimal published research. Although the public service is only one area in which the S-L Therapist may practise, the study highlights issues specific to this context as well as to the profession of S-L Therapy in general.

The lived experience of being a S-L Therapist in a public health service is one of challenge, opportunity, security, predictability and connectedness through diverse and complex relationships. The profession of S-L Therapy and the holistic nature of the work impact on the therapist's entire being - physical, mental and emotional. The joy of helping is contrasted with the exhaustion and despair where S-L Therapists do not feel that they make a difference. Despite this, however, S- L Therapists are committed to their chosen profession and to the clients and patients who need them.

\section{References}

Akroyd, D., Wilson, S., Painter, J., \& Figuers, C. (1994). Intrinsic and extrinsic predictors of work satisfaction in ambulatory care and hospital settings. Journal of Allied Health, 23, 3, 155-164.

Arbore, P., Katz, R.S., \& Johnson, T.A. (2006). When Professionals
Weep: Emotional And Countertransference Responses in End-ofLife Care. Routledge: New York.

Aron, M. L. (1991). Perspectives. The South African Journal of Communication Disorders, 38, 3-11.

Austin, V., Shah, S., \& Muncer, S. (2005). Teachers stress and coping strategies used to reduce stress. Occupational Therapy International, 12, 2, 63-90.

Bailey, D. M. (1990). Reasons for attrition from occupational therapy. American Journal of Occupational Therapy, 44, 1, 23-29.

Benierakis, C. E. (1995). The function of the multidisciplinary team in child psychiatry - clinical and educational aspects. $\mathrm{Ca}$ nadian Journal of Psychiatry, 40, 348-353.

Bloom, S. W., \& Summey, P. (1978). Models of the doctor-patient relationship; a history of the social system concept. In E. B. Galagher, (Ed.), The Doctor-patient relationship in the changing bealth scene (pp. 17-41). Washington, DC: US Dept of HEW.

Bortz, M. A., Jardine, C. A., \& Tshule, M. (1996). Training to meet the needs of the communicatively impaired population of South Africa: a project of the University of the Witwatersrand. European Journal of Disorders of Communication, 31, 465-476.

Boyd, S., \& Hewlett, N. (2001). The gender imbalance among speech and language therapists and students. International Journal of Language and Communication Disorders, 36, Suppl. 167-172.

Bratten. J., Callinan, M., Forshaw, C., \& Sawchuk, P. (2007). Work and organizational behaviour. New York: Palgrave MacMillan.

Byng, S., Cairns, D., \& Duchan, J. (2002). Values in practice and practising values. Journal of Communication Disorders, 35, 89106.

Carson, J., Wood, M., White, H., \& Thomas, B. (1997). Stress in mental health nursing: Findings from the mental health care survey. Mental Health Care, 1, 11-14.

Chang, E., \& Hancock, K. (2003). Role stress and role ambiguity in new nursing graduates in Australia. Nursing and Health Sciences, 5, 155-163.

Cheng, Y., Kawachi, I., Coakley, E., Schwart, Z. J., \& Colditz, G. (2000). Association between psychological work characterises and health functioning in American women. British Medical Journal, 320, 1432-1436.

Cherniss, C. (1995). Beyond burnout: Helping teachers, nurses, therapists $\mathcal{E}^{\circ}$ lawyers recover from stress $\mathcal{E}^{\circ}$ disillusionment. London: Routledge.

Colaizzi, P. F. (1978). Psychological Research as the Phenomenologist Views it. In R. Valle \& M. King (Eds.), Existential-phenomenological alternatives for psychology (pp. 48-71). New York: Oxford University Press.

Collings, J. A., \& Murray, P. J. (1996). Predictors of stress amongst social workers: An empirical study. British Journal of Social Work, 26, 375-387.

Creswell, J. W. (1998). Qualitative Inquiry and Research Design. Choosing among the Five Traditions. Thousand Oaks: SAGE Publications.

Culbreth, J. R., Scarborough, J. L., Banks-Johnson, A:, \& Solomon, S. (2005). Role stress among practicing school counsellors. Counselor Education E' Supervision, 45, 58-71.

Curtis, K. A., \& Martin, T. (1993). Perceptions of acute care physical therapy practice: issues for physical therapist preparation. Physical Therapy, 73, 581-598.

Deckard, G. J., \& Present, R. M. (1989). Impact of role stress on physical therapists' emotional and physical well-being. Physical 
Therapy, 69, 713-718.

Decker, F. (1997). Occupational and non-occupational factors in job satisfaction and psychological distress among nurses. Research in Nursing and Health, 20,453-464.

de Wesley, A. B., \& Clemson, L. (1992). Job satisfaction issues: The focus group approach. Australian Occupational Therapy Journal, 39, 7-15.

Egan, G. (2002). The skilled helper. A problem-management and opportunity-development approach to belping $\left(7^{\text {th }}\right.$ ed). Pacific Grove: CA, Brooks/Cole Thomson Learning.

Engel, G. L. (1977). The need for a new medical model: a challenge for biomedicine. Science, 196, 4286, 129-136.

Fadlon, J., \& Werner, S. (1999). The Relationship between Health Practitioner and Patient. In E. L. Ramsden (Ed.), The person as patient: Psychosocial perspectives for the healt $b$ care professional (pp. 197-211). London: Harcourt Brace and Company Ltd.

Farmer, R. E., Monahan, L. H., \& Hekeler, R. W. (1984). Stress management for buman services. Beverley Hills: SAGE Publications Inc.

Flasher, L., \& Fogle, P. T. (2004). Counselling skills for speech-language patbologists and audiologists. New York: Thomson Delmar learning.

Frattali, C. (2001). Professional autonomy and collaboration. In R. Lubinski \& C. Frattali (Eds.), Professional issues in speech-language pathology and audiology (2nd ed.). (pp. 173-182). San Diego: Singular Publishing Group Inc.

Freda, M. (1992). Retaining occupational therapists in rehabilitation settings: Influential factors. American Journal of Occupational Therapy, 46, 240-245.

Guba, E. G., \& Lincoln, Y. (1989). Fourth generation evaluation. Newbury Park, California: SAGE Publications.

Harrison, W. D. (1983). Burnout. In T. Keefe \& D. E. Maypole (Eds.), Relationships in social service practice: Context and skills. (pp. 207-232). Monterey: Brooks/Cole Publishing Company.

Hasselkus, B. R., \& Dickie, V. A. (1994). Doing occupational therapy: Dimensions of satisfaction and dissatisfaction. American Journal of Occupational Therapy, 48, 2, 145-154.

Henri, B. P. \& Hallowell, B. (2001). Improving access to speechlanguage pathology and audiology services. In R. Lubinski \& C. Frattali (Eds.), Professional issues in speech-language pathology and audiology (2 $2^{\text {nd }}$ ed). (pp. 337-357). San Diego: Singular Publishing Group, Inc.

Holland, A. (2001). Foreword. In R. Lubinski \& C. Frattali (Eds.), Professional issues in speech-language pathology and audiology (2 $2^{\text {nd }}$ ed). (pp. xi-xii). San Diego: Singular Publishing Group, Inc.

Holloway, I., \& Wheeler, S. (1996). Qualitative research for nurses. Oxford: Blackwell Science.

Hycner, R. H. (1985). Some guidelines for the phenomenological analysis of interview data. Human Studies, 8, 279-303.

Jenkins, M. (1991). The problems of recruitment: A local study. British Journal of Occupational Therapy, 54, 449-452.

Jenkins, R., \& Elliot, P. (2004). Stressors, burnout and social support: nurses in acute mental health settings. Journal of Advanced Nursing, 48, 6, 622-631.

Kilfedder, C. J., Power, K. G., \&Wells, T.J. (2001). Burnout in psychiatric nursing. Journal of Advanced Nursing, 34, 383-396.

Krefting, L. (1991). Rigor in qualitative research: The assessment of trustworthiness. The American Journal of Occupational Therapy, $45,3,214-222$.

Lincoln Y. \& Guba E. (1985) Naturalistic inquiry. Newbury Park:
SAGE Publications.

Lloyd, C., \& King, R. (2001). Work-related stress and occupational therapy. Occupational Therapy International, 8, 4, 227-243.

Lloyd, C., King, R., \& Chenoweth, L. (2002). Social work, stress and burnout: A review. Journal of Mental Health, 11, 3, 255265.

Lubinski, R. \& Frattali, C. (2001). Professional issues in speech-language pathology and audiology ( $2^{\text {nd }}$ ed.). San Diego: Singular Publishing Group, Inc.

Maslach, C. (1982). Burnout - The cost of caring. New Jersey: Prentice-Hall Inc.

Mason, J. (1996). Qualitative Researching. London: SAGE Publications Inc.

Maxwell, D. L., \& Satake, E. (2006). Research and statistical methods in communication sciences and disorders. New York: Thomson Delmar Learning.

McGibbon, G. (1997). The ward sister/charge nurse as 'on site' manager, Nursing Standard, 11, 34-37.

Miller, P. A., Solomon, P., Giacomini, M., \& Abelson, J. (2005). Experiences of novice physiotherapists adapting to their role in acute care hospitals. Physiotherapy Canada, 57, 2, 145-153

Moore, K., Cruikshank, M., \& Haas, M. (2006a). Job satisfaction in occupational therapy: a qualitative investigation in urban Australia. Australian Occupational Therapy Journal, 53, 18-26.

Moore, K., Cruikshank, M., \& Haas, M. (2006b). The influence of managers on job satisfaction in occupational therapy. British Journal of Occupational Therapy, 69, 7, 312-318.

Murray, T. (1998). From outside the walls: A qualitative study of nurses who recently changed from hospital-based practice to home health care nursing. Journal of Continuing Education in Nursing, 29, 55-60.

Ohman, A., Solomon, P., \& Finch, E. (2002). Career choice and professional preferences in a group of Canadian physiotherapy students. Advances in Physiotherapy, 4, 6-22.

Patton, M. Q. (2002). Qualitative Research EO Evaluation Methods (3rd ed.). Thousand Oaks: SAGE Publications.

Payne, R., \& Frith-Cozens, J. (1987). Preface. In R. Payne \& J. Frith-Cozens (Eds.), Stress in Health Professionals. (pp. xi-xii). London: John Wiley \& Sons Ltd.

Pope, E., Nel, E., \& Poggenpoel, M. (1998). The experience of registered nurses nursing in the general adult intensive care unit: A phenomenological qualitative research study. Curationis, 21, 32-38.

Pringle, E. (1996). Occupational therapy in the reformed NHS: the views of therapists and therapy managers. British Journal of Occupational Therapy, 59, 9, 401-406.

Purtilo, R. (1990). Health professional and patient interaction ( $4^{\text {th }}$ ed). Philadelphia: Harcourt Brace \& Company.

Randolph, D. S. (2005). Predicting the effect of extrinsic and intrinsic job satisfaction factors on recruitment and retention of rehabilitation professionals. Journal of Healtbcare Management, 50,1, 49-60.

Reid, Y., Johnson, S., Morant, N., Kuipers, E., Szmukler, G., Thornicroft, G., Bebbington, P., \& Prosser, D. (1999). Explanations for stress and satisfaction in mental health professionals: a qualitative study. Social Psychiatry and Psychiatric Epidemiology, 34, 301-308.

Sahler, A. (2002). Evolving models of health care. Retrieved March $13,2007$.

Schofield, M., \& Jamieson, M. (1999). Sampling in quantitative 


\section{JOCELYN A. WARDEN, PATRICIA MAYERS AND HARSHA KATHARD}

research. In V. Minichiello, G. Sullivan, K. Greenwood \& R Axford (Eds.), Handbook for research methods in bealth sciences. (pp. 147-172). Sydney: Addison-Wesley Longman.

Shenton, A. (2004). Strategies for ensuring trustworthiness in qualitative research projects. Education for Information, 22, 6175.

Sheridan, J. (1999). A career in speech and language therapy: For white women only? Bulletin of the Royal College of Speech and Language Therapists, 562, 3.

Smith, M. \& Nursten, J. (1998). Social workers' experiences of distress - Moving towards change? British Journal of Social Work, 28, 351-368.

Stone, J. R. (1992). Resolving relationship problems in communication disorder treatment: A systems approach. Language, Speech, and Hearing Services in Schools, 23, 300-307.

Swidler, M., \& Ross, E. (1993). Burnout: A smouldering problem amongst South African speech-language pathologists and audiologists? The South African Journal of Communication Disorders, 40, 71-84.

Tryssenaar, J., \& Perkins, J. (2001). From student to therapist: Exploring the first year of practice. American Journal of Occupa- tional Therapy, 55, 19-27.

Tuomi, S. K. (1994). Speech-language pathology in South Africa: A profession in transition. American Journal of Speech-Language Pathology, 3, 5-11.

Um, M. Y., \& Harrison, D. F. (1998). Role stressors, burnout, mediators, and job satisfaction: A stress-strain-outcome model and an empirical test. Social Work Research, 22, 100-115.

Van Manen, M. (1990). Researching lived experience: Human science for action sensitive pedagogy. New York: State University of New York Press.

Van Rensburg, H. C. J. (2004). Primary Health Care in South Africa. In H. C. J. van Rensburg (Ed.), Health and Health Care in South Africa (pp. 412-458). Pretoria: Van Schaik Publishers.

Van Wijk, C. (1997). Factors influencing burnout and job stress among military nurses. Military Medicine, 162, 707-710.

Webster, L., \& Hackett, R. (1999). Burnout and leadership in community mental health systems. Administrative Policy in Mental Health, 25, 387-399.

Worrall, L. E., \& Frattali, C.M. (2000). (Eds.). Neurogenic communication disorders: A functional approach. New York: Thieme. 